\title{
Influence of body mass index and work activity on the prevalence of median mononeuropathy at the wrist
}

\author{
Robert A Werner, Alfred Franzblau, James W Albers, Thomas J Armstrong
}

Department of Physical Medicine and Rehabilitation

R A Werner

Department of Neurology, University of Michigan Medical Center, Ann Arbor, MI, USA

J W Albers

Physical Medicine and Rehabilitation Service, Veterans Affairs Medical Center Ann

Arbor, MI, USA

R A Werner

Department of Environmental and Industrial Health School of Public Health University of Michigan Ann Arbor, MI, USA

R A Werner

A Franzblau

J W Albers

T J Armstrong

Correspondence to:

Dr R A Werner, Ann Arbor

VAMC, 2215 Fuller Rd

(117), Ann Arbor, MI

48105, USA

Accepted 6 November 1996

Table 1 Personal factors related to the occurrence of carpal tunnel syndrome

Medical conditions:
Diabetes
Thyroid disease
Connective tissue
disorders
Amyloidosis
Acromegaly
Vitamin B6 deficiency (?)
Age
Sex
Use of oral contraceptives
Oophorectomy
Wrist dimension
Weight
Stature
Body mass index

\begin{abstract}
Objective-To determine which proposed risk factor, work activity (industrial $v$ clerical), body mass index (BMI), or other demographic factors had the most influence on the prevalence of median mononeuropathy at the wrist, and if there was an interaction between the risk factors.

Methods-This was a cross sectional study of active workers at five different worksites; four were industrial sites and one was clerical. 527 workers were recruited-164 clerical and 363 industrial. The presence of a median mononeuropathy in either hand was measured by electrodiagnostic techniques comparing median and ulnar sensory latencies.

Results-30\% of workers had an abnormality of the median sensory nerve at the wrist (34\% of the industrial $v 21 \%$ of the clerical workers). The adjusted risk for industrial workers was twice that of clerical workers. Obese workers $($ BMI > 29) were four times more likely to present with a median mononeuropathy than workers who were normal or slender (BMI < 25). There was no significant interaction between BMI and worksite in relation to median mononeuropathy. Increasing age was also related to an increased risk of median mononeuropathy.

Conclusions-Obesity, industrial work, and age are independent risk factors that influence the prevalence of median mononeuropathies among active workers.
\end{abstract}

(Occup Environ Med 1997;54:268-271)

Keywords: median nerve; carpal tunnel syndrome; obesity; epidemiology

There are many factors that are thought to place a person at risk of the development of carpal tunnel syndrome (CTS). There has been a tremendous increase in the numbers of cases of CTS reported among workers. This has been noted among industrial as well as clerical workers. The highest incidence of CTS is among meat packers, knit underwear mills, car manufacturers, and poultry processing plants. ${ }^{1}$ These workers have three and four times the incidence of other industries and even more compared with clerical workers. ${ }^{12}$ Carpal tunnel syndrome is one of several disorders of the muscles, tendons, and nerves that affect people performing hand intensive work.

Several studies suggest that repetition, awkward posture, high force, vibration, and local pressure increase the risk for CTS. ${ }^{35}$ Despite this, some investigators have attributed the greatest risks to host specific or personal factors, particularly obesity. ${ }^{6}$ Numerous personal factors have been reported (table 1)..$^{7-9}$ Werner et $a l^{10}$ showed that body mass index (BMI) was related to a higher prevalence of median mononeuropathies among a hospital based population. Several other investigators have reported that people with CTS were heavier and shorter than the general population. ${ }^{468911}$ Vessey et $a l^{12}$ found that the risk of CTS among obese women was double that of slender women and we $\mathrm{e}^{10}$ found a $250 \%$ increase in risk of a median mononeuropathy among obese compared with slender subjects.

Within an industrial population, Nathan et $a l^{6}$ showed that a higher BMI was associated with a higher prevalence of median mononeuropathy. They found a relative risk (RR) of $4 \cdot 1$ for obese people compared with slender ones. This study was weakened by potential methodological flaws, of which the most prominent was an analysis that used both hands of a person as unique data instead of the data being analysed on the basis of the person. ${ }^{1314}$

The goals of our present study were to find: (a) the association of BMI with median mononeuropathy as measured by $R R$ within a large working population, (b) the RR of finding a median mononeuropathy in industrial versus clerical settings, $(c)$ whether an interaction existed between the worksite and BMI, and (d) the effect of age, sex, or pre-existing conditions as independent or interactive factors. We recognise that CTS is a group of specific signs and symptoms associated with impairment of the median nerve in the wrist but as a true gold standard for the clinical diagnosis does not exist, we chose to use electrodiagnostic findings irrespective of symptoms (median mononeuropathy) as the primary outcome measure as they are objective findings that are very sensitive in diagnosing CTS.

\section{Methods}

A cross sectional screening research design was used to test the median and ulnar sensory evoked responses of active workers in five different settings within the midwest United States. The industrial sites included produc- 
tion line workers from two manufacturers of car parts, a furniture manufacturer, and a manufacturer of paper containers; the light duty site included clerical staff of an insurance company. There was an average participation rate of $75 \%$, with a range of $56 \%$ to $89 \%$, among eligible workers at the five study sites. Only one site had a participation rate below $75 \%$; this industrial site did not allow testing in company time. Industrial workers were selected to be representative of the range of jobs typically found in contemporary manufacturing sites. They included jobs in three categories of hand repetition: high, medium, and low repetition in manufacturing jobs with an equal number in each category. The jobs were rated on a scale 1 to 10 for frequency of hand repetition $(0=$ idle, $2=$ frequent pauses, $4=$ slow steady motion, $6=$ steady motion, $8=$ rapid steady motion, and $10=$ rapid steady motion, difficulty keeping up). Each job category was rated by a group of industrial engineers and hygienists on the visual analogue scale already mentioned from a video of the job. The jobs ranged from loading machines and monitoring their operations to highly repetitive hand transfer and assembly operations. Office jobs ranged from incidental use of keyboards to medium use in conjunction with claims processing. Although the office jobs did not require extremely high rates of hand exertion or movement, the workers hands were not idle and were not considered to be unexposed to repetitive hand work. This paper was primarily concerned with the relative difference between office workers and manufacturing workers.

Subjects signed a written consent form that was approved by the Review Board of our Institution and each subject completed a symptoms questionnaire. Their height and weight were measured. Age, sex, and medical history were self reported within the questionnaire.

Electrodiagnostic studies of the median and ulnar sensory nerve were conducted bilaterally with the techniques described by Kimura. ${ }^{15}$ The tests were performed with antidromic supramaximal stimulation, a distance of $14 \mathrm{~cm}$, and ring recording electrodes placed around digits 2 and 5. A standard distance of 3 $\mathrm{cm}$ was used between electrodes. Hand temperature was recorded and the hand was warmed if the midpalmar temperature was below $32^{\circ} \mathrm{C}$. All studies were performed on site by an electromyographer certified by the American Board of Electrodiagnostic Medicine (ABEM) and a certified electrodiagnostic technician on a TECA TD 20 (TECA, Pleasantville, NY). The peak latency and the amplitude (baseline to peak) were recorded for each sensory nerve.

A median mononeuropathy was defined as median sensory peak latency of $\geqslant 0.5 \mathrm{~ms}$ longer than the ulnar sensory peak latency (MM5). Also, a more conservative definition $(0.8 \mathrm{~ms}$ longer) was used for some analyses (MM8). Median mononeuropathy was used as the primary outcome measure as opposed to symptoms consistent with CTS. This allowed an objective measure of the physiological health of the median nerve at the wrist but was not a direct measure of CTS as that would be based upon clinical presentation.

The BMI was calculated from the measured height and weight and expressed in $\mathrm{kg} / \mathrm{m}^{2}$. The definition of obesity was taken from the Michigan Department of Public Health. ${ }^{16}$ Thin was defined as a BMI less than $20 \mathrm{~kg} / \mathrm{m}^{2}$, normal was $20-25 \mathrm{~kg} / \mathrm{m}^{2}$, heavy was $25-$ $29 \mathrm{~kg} / \mathrm{m}^{2}$, and obese was $>29 \mathrm{~kg} / \mathrm{m}^{2}$.

The statistical analyses was performed with STATA. ${ }^{17}$ The RR was estimated with the odds ratio (OR) calculated during logistic regression modelling. If the $95 \%$ confidence interval $(95 \% \mathrm{CI})$ included 1.0 , the $\mathrm{RR}$ was not significant at the $P=0.05$ level. Presence of a median mononeuropathy was the dependent variable and BMI, age, sex, work setting, hand temperature, pre-existing condition, and wrist dimension were considered as independent variables and were fitted into the model. Models were run with all workers and again with women only as the clerical workers were predominantly female.

\section{Results}

The median (range) age among the 527 workers was $34(18-70)$ years; $61 \%$ were women. There were 164 clerical and 363 industrial workers. There was no significant difference in age from site to site but the sex ratio did differ. Among the industrial sites, the percentage (range) of women workers was $49 \%$ (36\%$74 \%$ ) whereas the clerical workers were $87 \%$ women.

Among the industrial sites the prevalence of a MM5 was $34 \%$ versus $21 \%$ among clerical workers. When MM8 was used, the prevalence was $13 \%$ versus $9 \%$. Clerical and industrial workers both had a prevalence of $30 \%$ obesity defined by a BMI $>29$. The mean (SD, range) $\mathrm{BMI}$ in this population was 28 (6, 18-50). This is consistent with the state of Michigan which has the second highest rate of obesity in the country. The figure shows the distribution of median mononeuropathies stratified by BMI latency and worksite. The $\chi^{2}$ for each of the individual definitions of a median mononeuropathy versus BMI was significant at $P<0.01$. The MM8 had fewer

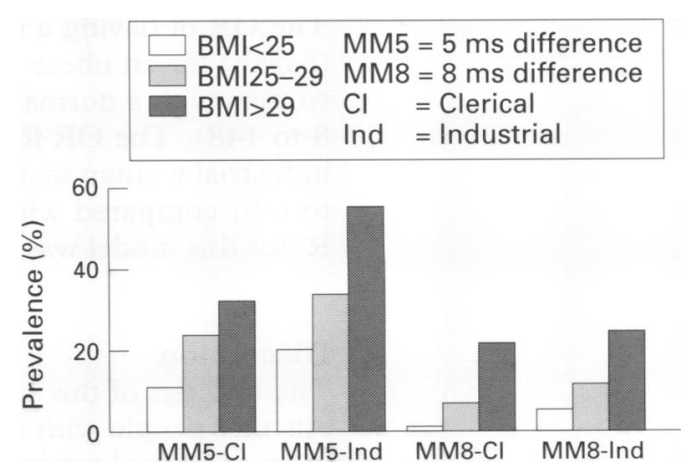

The prevalence (\%) of median mononeuropathies as defined by $0.5 \mathrm{~ms}$ (MM5) and $0.8 \mathrm{~ms}$ (MM8) differences in clerical and industrial sites, stratified by BMI group. 
Table 2 ORs (95\% CIs) for presenting with a median mononeuropathy at the wrist associated with several risk factors, including BMI, age, and work activity, controlling for other factors (this was calculated with a logistic regression with presence or absence of $a$ median mononeuropathy as the dependent variable)

\begin{tabular}{lll}
\hline Risk factors & MM5 & $M M 8$ \\
\hline BMI (Obese: normal or thin) & $4 \cdot 0(2.4$ to 6.4$)$ & $7 \cdot 4(3.3$ to 16.6$)$ \\
BMI (10 point difference) & $3 \cdot 4(3.3$ to 3.5$)$ & $3.5(3.4$ to 3.6$)$ \\
Age (10 year difference) & $3.3(3.3$ to 3.4$)$ & $3.5(3.4$ to 3.5$)$ \\
Work activity (industrial: clerical) & $2 \cdot 0(1.3$ to 3.2$)$ & $1.7(0.9$ to 3.4$)$ \\
\hline
\end{tabular}

MM5 = median mononeuropathy defined by a $0.5 \mathrm{~ms}$ difference between median and ulnar sensory latencies; MM8 = median mononeuropathy defined by a $0.8 \mathrm{~ms}$ difference between median and ulnar sensory latencies.

cases defined but the same relation existed for increasing prevalence of median mononeuropathy with increasing BMI.

To ascertain an estimate of the RR of BMI and work setting, a logistic regression model was performed. This allowed an estimate of an individual factor when controlling for other factors as well as determining whether there is any significant interaction between the variables. The logistic regression model found that the only significant factors were BMI, age, and worksite. Interaction terms included BMI and worksite, age and worksite, and BMI and age. Table 2 shows the OR (an estimate of the RR) of these factors and the $95 \%$ CIs for each definition of a median mononeuropathy. The influence of BMI was similar if used as a continuous or categorical variable. The ORs of a median mononeuropathy, defined by a $0.5 \mathrm{~ms}$ difference, were four times greater among obese people than among normal or thin people; the ORs increased to $7 \cdot 4$ times if a more conservative definition, $0.8 \mathrm{~ms}$ difference, was used. Alternatively, for each increase of 10 in the BMI, and for each 10 year age increase there was a threefold greater OR of having a median mononeuropathy. Workers in an industrial setting had twice the ORs of having a median mononeuropathy compared with clerical workers. The model for MM8 explained $16 \%$ of the variance and the model for MM5 explained $12 \%$ of the variance. No interaction terms were significant. Adding sex, height, weight, wrist dimension, hand temperature, or industrial site did not add to the significance of the model.

When only women were included in the model, the findings were similar but there was a more pronounced effect for BMI and industrial setting. This relation held true for both the models (MM5 and MM8) although the model for MM8 had the strongest relation. The OR of having a median mononeuropathy (MM8) for an obese woman compared with a woman with a normal BMI was 33.7 (95\% CI 8 to 148). The OR for finding on MM8 in an industrial woman worker was $2 \cdot 6(95 \% \mathrm{CI} 1 \cdot 1$ to 6.0 ) compared with a clerical worker. The $\mathrm{R}^{2}$ for this model was $0 \cdot 32$.

\section{Discussion}

The findings of this study support the hypothesis that people with a higher BMI or working in an industrial setting are at increased risk of median mononeuropathy. Also, age was an independent risk factor. After inclusion of BMI, other anthropometric measures were not significant independent risk factors. Because the clerical workers were predominantly women, there were few male clerical workers for comparison. The model of the entire population did not find sex a significant independent risk factor but stratified analysis of women in the sample did show a higher risk of a median mononeuropathy among obese women and women in industry.

How the pathophysiology of obesity could explain this relation is not well understood. Letz and Gerr ${ }^{18}$ found the same relation between obesity and slow conduction of the median nerve across the wrist in a large population based study but a slight inverse relation was found between obesity and other peripheral nerve measures. The conduction velocity of the peroneal, sural, and ulnar nerves all tended to improve among subjects who were more obese whereas only the median sensory nerve across the wrist slowed. If a causal relation between obesity and a slowing of median conduction across the wrist exists, it may relate to increased fatty tissue or to increased hydrostatic pressure within the carpal canal in obese people compared with normal or slender people. Magnetic resonance imaging has shown increased fatty tissue in the carpal canal being associated with CTS in one patient ${ }^{19}$ but there has not been a systematic study of the anatomy within the carpal canal in obese compared with slender people. Likewise pressures within the carpal canal have been shown to be higher in people with CTS, ${ }^{20-22}$ but the relation between body size and pressure within the carpal canal has not been explored.

The median nerve at the wrist is more compartmentalised than the ulnar, peroneal, or sural nerves and may be subjected to compression due to fatty build up within the carpal canal among obese people. Conversely, heavier people may simply place more mechanical stress on their hands and wrists and thus place the median nerve at higher risk as opposed to some intrinsic change within the carpal canal. The possible association between obesity and the development of early type II diabetes may be a confounder but is not related to the workers' reported diabetes.

Alternatively, thinner subjects may be indicative of a person's overall conditioning which may in term influence the performance of the median nerve.

Work activity has long been suspected of being an independent risk factor for the development of CTS. We used an objective measure of the physiological response of the median nerve across the wrist and compared it with the physiological response of the ipsilateral ulnar nerve across the wrist and showed that workers in industrial manufacturing sites had a higher prevalence of slowing of the median nerve across the wrist (median mononeuropathy) than did clerical workers when controlling for other factors. We did not define the specific ergonomic exposure of each worker but compared a group of industrial labourers with clerical workers. The study of Nathan et $a l^{6}$ of industrial workers did not show a significant work related factor and 
attributed most of the explainable variance to obesity. In contrast, we found that work activity was a significant independent risk factor.

The increased risk of median mononeuropathy among industrial workers has been suspected but not convincingly shown before in electrodiagnostic studies although Stetson et $a l^{23}$ did show that the mean amplitude and latency of the median sensory evoked response was smaller and more prolonged in asymptomatic active industrial workers than in managerial office workers. Studies suggesting that work factors such as force, posture, vibration, and local hand contact increased the risk of CTS were based upon symptoms and findings from physical examinations such as a positive Tinel's or Phalen's manoeuvre. ${ }^{3}$ The study of Nathan et al has been reanalysed to show a significant risk of high intensity industrial work when compared with light work. ${ }^{14}$ Neither the previous studies nor our present study have developed a model of CTS that effectively explained a large amount of the variance despite the use of demographics, anthropometric characteristics, or job descriptions. The type of job and degree of obesity do play a part but this is a multifactorial problem and the other risk factors are not obvious. Perhaps the individual variations in the carpal canal anatomy and the resultant pressures within the carpal canal hold the key, but this relation needs further study. What remains to be done is a prospective study that would show changes over time in a high risk population and a relative lack of change in a low risk population.

There does not seem to be any significant interaction between obesity and work activity. Each is an independent risk factor and the risk for the individual worker is additive. Caution must be used in interpreting this data. Not all industrial workers develop a median mononeuropathy and not all obese workers develop CTS. A proposed mechanism of occupational median nerve injury at the wrist associates synovial thickening and gradual increase in the pressure within the carpal canal with repeated wrist flexion and extension. We are currently exploring the possibility of fatty deposits in the carpal canal and associated increased pressure among obese subjects.

This study does not attempt to determine the RR of the clerical worker compared with the general population. We did find a $9 \%-21 \%$ prevalence of median mononeuropathy among clerical workers, which is higher than the $3 \%-5 \%$ that would be expected in a normal healthy population based on the normal values derived in our electrodiagnostic laboratory as well as several other reports of normal values for median and ulnar sensory latencies. ${ }^{1324} \mathrm{It}$ seems that there is an exposure-response relation to intensive activity of the hand with the unexposed population having a low prevalence $(<5 \%)$ of median mononeuropathies, clerical workers having an intermediate level $(20 \%)$, and industrial workers having a high prevalence $(33 \%)$. The prevalence of a median mononeuropathy among the industrial sites varied from $25 \%$ to $51 \%$. This is consistent with other cross sectional studies of occupational risks of carpal tunnel syndrome. ${ }^{121425}$ Although the present study does not prove causality, the resulting association does provide an avenue for intervention. In many instances it is possible to use mechanical assistance to hold and transport work objects and to schedule work in ways that minimise exposure to repetitive hand movements.

This research was supported, in part, by grant number RO1OH02941-01 from the National Institute for Occupational Safety and Health, and also by Aetna Life Insurance Company. Its contents are solely the responsibility of the authors and do not necessarily represent the official views of the National not necessarily represent the official views of the National
Institute for Occupational Safety and Health or the Aetna Life Insurance Company.

1 Franklin GM, Haug J, Heyer N, Checkoway H, Peck N. Occupational carpal tunnel syndrome in Washington State, 1984-8. Am $\mathcal{f}$ Public Health 1991;82:741-6.

2 Hanrahan LP, Higgins D, Anderson H, Haskins L, Tai S. Project SENSOR: Wisconsin surveillance of occupational carpal tunnel syndrome. Wis Med $\not{f} 1991 ; 90$ $80,82-3$. 3 Silverstein BA, Fine LJ, Armstrong TJ. Occupational fac-
tors and carpal tunnel syndrome. Am f Ind Med 1987; 11:343-58.

4 Falck B, Aarnio P. Left-sided carpal tunnel syndrome in butchers. Scand $\mathcal{F}$ Word Environ Health 1983;9:291-7.

5 Wieslander G, Norback D, Gothe CJ, Juhlin L. Carpal Wieslander G, Norback D, Gothe CJ, Juhlin L. Carpal
tunnel syndrome (CTS) and exposure to vibration, repettunnel syndrome (CTS) and exposure to vibration, repetitive wrist movements, and heavy manual
referent study. $B r \mathcal{F}$ Ind Med 1989;46:43-7.

6 Nathan PA, Keniston RC, Myers LD, Meadows KD. Obesity as a risk factor for slowing of sensory conduction of the median nerve in industry: a cross-sectional and longitudinal study involving 429 workers. $\mathcal{F}$ Occup Med 1992;34:379-83.

7 Armstrong TJ, Chaffin DB. Carpal tunnel syndrome and selected personal attributes. $\mathcal{F}$ Occup Med 1979;21:481-6.

8 de Krom MC, Kester AD, Knipschild PG, Spanns F. Risk factors for carpal tunnel syndrome. Am $\mathcal{F}$ Epidemiol 1990; 132:1102-10.

9 Dieck GS, Kelsey JL. An epidemiologic study of the carpal tunnel syndrome in an adult female population. Prev Med 1985;14:63-9.

10 Werner RA, Albers JW, Franzblau A, Armstrong TJ. The relationship between body mass index and the diagnosis of carpal tunnel syndrome. Muscle Nerve 1994;17:632-6.

11 Cannon LJ, Bernacki EJ, Walter DS. Personal and occupational factors associated with carpal tunnel syndrome. $\mathcal{f}$ Occup Med 1982;23:255-8.

12 Vessey MP, Villard-Mackintosh L, Yeates D. Epidemiology of carpal tunnel syndrome in women of childbearing age. Findings in a large cohort study. Int $\mathcal{f}$ Eearing age. Findings in

13 Gerr F, Letz R. Risk factors for carpal tunnel syndrome in industry: blaming the victim? $\mathcal{f}$ Occup Med 1992;34: 1117-8.

14 Stock SR. Workplace ergonomic factors and development of musculoskeletal disorders of the neck and upper limbs: a meta-analysis. Am F Ind Med 1991;19:87-107.

15 Kimura J. Electrodiagnosis in diseases of nerve and muscle principles and practice. Philadelphia: FA Davis, 1983.

16 Anderson JV, Rafferty AP. Overweight. In: Health risk behaviors, 1991. Lansing, MI: Michigan Department of Public Health, 1992.

17 Stata Corporation. Stata statistical software, release 4.0. College Station, TX: Strata Corporation, 1995.

18 Letz R, Gerr F. Covariates of human peripheral nerve function: I nerve conduction velocity and amplitude. Neurotoxicol Teratol 1994;16:95-104

19 Masgaradeh M, Schneck CD, Bonakdarpour A, Mitra A, Conaway D. Carpal tunnel: MR imaging part II. Carpal tunnel syndrome. Radiology 1989;171:749-54.

20 Gelberman RC, Hergenroeder PT, Hargens AR, Lundborg GN, Akeson WH. The carpal tunnel syndrome: a study of carpal canal pressure. $\mathcal{F}$ Bone foint Surg (Am) 1981;63: 380-3.

21 Szabo RM, Chidgey LK. Stress carpal tunnel pressures in carpal tunnel patients and normal patients. $\mathcal{f}$ Hand Surg 1989;15:624-8.

22 Werner CO, Elmqvist D, Ohlin P. Pressure and nerve lesion in the carpal tunnel. Acta Orthop Scand 1983; 54:312-6.

23 Stetson DS, Silverstein BA, Keyserling W, Wolfe RA, Albers JW. Median sensory distal amplitude and latency: comparisons between non-exposed managerial professional employees and industrial workers. Am $\mathcal{F}$ Ind Med 1993;24:175-89.

24 Stevens JC, Sun S, Beard CM, O'Fallon WM, Kurland LT. Carpal tunnel syndrome in Rochester, Minnesota, 1961-80. Neurology 1988;38:134-8.

25 Armstrong TJ, Buckle P, Fine LJ, Hagberg M, Jonsson B, Kilbom A, et al. A conceptual model for work-related neck and upper-limb musculoskeletal disorders. Scand $\mathcal{f}$ Work Environ Health 1993;19:73-84. 